(RESEARCH ARTICLE)

\title{
Effects of drought stress on early seedling growth and ecophysiology of beans, pepper, tomato and watermelon grown in screenhouse-potted soil
}

\author{
Tabot Pascal Tabi *, Mfombep Priscilla Mebong and Odine Stephinia Wase \\ Department of Agriculture, Higher Technical Teachers' Training College Kumba, University of Buea. P.O. Box 249 \\ Kumba, Cameroon.
}

Publication history: Received on 20 July 2020; revised on 22 August 2020; accepted on 25 August 2020

Article DOI: https://doi.org/10.30574/wjarr.2020.7.2.0271

\begin{abstract}
With changing rainfall patterns, deforestation and degradation of arable land, freshwater resources for irrigation are reducing, increasing the potential for drought stress on crops. The aim of this research was to study the growth and ecophysiological responses of beans, pepper, tomato and watermelon potted and grown in screenhouse under varied irrigation, for 14 days. There were three treatments: zero irrigation after seedling establishment, $0.1 \mathrm{~L} /$ pot/week, 0.2 $\mathrm{L} /$ pot/week and $0.3 \mathrm{~L} /$ pot/week respectively, each pot with three plants, in a completely randomized design with 3 replicates. Growth and ecophysiological measurements were recorded for the first three weeks of growth. ANOVA and Pearson Correlation were conducted, with significance at $\alpha 0.05$. Plants with zero irrigation had the least growth in all parameters measured; growth was stimulated by irrigation, with a threshold at $0.2 \mathrm{~L} /$ week (corresponding to 2200 $\mathrm{mm}$, the mean annual rainfall for the region) for pepper, tomato and watermelon seedlings. Biomass accumulation in all species increased with irrigation but WUE decreased. The quantum efficiency of photosystem II photochemistry of beans and watermelon increased to 0.8 as irrigation increased, while pepper and tomato remained low in all treatments, indicating stress. These results show that early seedling stages are sensitive to drought; however, beans and watermelon seedlings were more resistant to soil moisture deficit than tomato and pepper seedlings. Early farm management should consider appropriate irrigation volumes for better and more vigorous crops in the field. This is essential in a future where irrigation water deficits are predicted to increase during the cropping seasons.
\end{abstract}

Keywords: Crop ecophysiology; Deficit irrigation; Drought stress; Photosystem II photochemistry; Water use efficiency; Potted soil

\section{Introduction}

Food security issues are a great concern to mankind, due to the increase of global population, average per capita income, and high demand for land for industrialization with concomitant limitation in the potential to increase suitable arable lands. Simultaneously, unsustainable development patterns and climate change are degrading the world's water resources at an alarming pace $[1,2]$. Therefore in the future, crop production is predicted to face two main challenges namely limited suitable land for natural expansion (space constraint) and limited irrigation water (an abiotic stressor).

It is widely accepted that global agricultural production is susceptible to growing environmental constraints $[3,4]$ in the form of abiotic and biotic stresses that adversely influence plants [5]. Abiotic stresses are the principal cause of crop losses, decreasing average yields for major crops by more than $50 \%[6,7]$ and threatening the entire agricultural industry. Among these environmental restrictions to crop production is drought or soil moisture deficit $[8,9]$ caused principally by degrading freshwater resources, deforestation, changing rainfall patterns, salinization or contamination of irrigation water sources, and changes in sea-surface temperatures $[10,11]$. Definitions of drought by the IPCC have been refined, and in agriculture, drought is now defined to embody soil moisture deficit. According to Trenbeth et al.

\footnotetext{
* Corresponding author: Tabot Pascal Tabi

Department of Agriculture, Higher Technical Teachers' Training College Kumba, University of Buea. P.0. Box 249 Kumba, Cameroon. 
[12], agricultural drought is defined as 'moisture deficit in the root zone of the soil (top 1 metre) that is of magnitude enough to impact crops'. In addition, soil-water relationships are important to plant growth and nutrient uptake [13]. Inadequate soil moisture for plant uptake is a result of shortage, irregular or delayed and inadequate precipitation in rainfed systems, or insufficient irrigation volumes in irrigated systems, and as a result, the plant suffers drought stress.

The effects of drought stress differ from plant to plant depending on their degree of tolerance to soil moisture deficit which is genetically coded $[14,15,16,17,18]$ but in the field, drought reduces crop growth, and in consequence yield levels also drop. In Drought-susceptible plants, this is often due to the fact that adaptive mechanisms for drought tolerance divert photosynthate from building biomolecules required for growth, to building biomolecules required for responding to the stress - the so-called growth-differentiation balance $[19,20]$. The mechanisms of tolerance to drought stress as with most abiotic stress, is centered on stress avoidance and resource re-allocation [21]. In the short term, crop plants would reduce leaf areas and/or increase leaf abscision, close stomata to reduce the rates of transpiration, hence conserving moisture, or increase root:shoot ratios for better moisture foraging [21, 22, 23]. The tradeoff of these mechanisms is a reduction in photosynthesis rates and shoot growth, with eventual low crop yields.

Responses to drought also depend on the developmental stage of the plant [24]. Most crop plants are propagated either from seeds or from very young seedlings, the survival of which determine the effective plant stand, and potentially, yields. Rapid relative growth rates at the seedling stage are an indication of how well the plants are accumulating biomass, and hence indicate their ability to compete for nutrients in the field [25]. A majority of Ecophysiological studies on crop plants are based on older seedlings and mature plants. However, the success of a crop depends on the vigor of its emergent seedling, so studies of early seedling responses to drought are necessary to guide future field establishment and management. Among the crops propagated through seeds and young seedlings are Phaseolus vulgaris L. (Beans), Citrullus lanatus (Thunb.) Matsum. \& Nakai (Watermelon), Capsicum annuum L. (Pepper) and Lycopersicon esculentum Mill. (Tomato). In the tropics, these are high valued horticultural crops that both form the staple food source and contribute significant earnings to the cultivating regions [26].

The aim of this study was to determine the early ecophysiological responses of beans, pepper, tomato and watermelon seedlings subjected to different irrigation regimes in screenhouse, in order to predict future field performance and recommend appropriate field management in different moisture availability scenarios.

\section{Material and methods}

\subsection{Study species}

The species studied include beans, pepper, tomato and watermelon. Beans (Phaseolus vulgaris L.) belongs to the family Fabaceae and is consumed as vegetable when immature, and as French Beans when fully mature and dry. The variety studied was the Cora variety, with dwarf growth habit, white seeds and maturity of about 40 days after emergence. Pepper (Capsicum annum L.) is a Solanaceae, grown mainly for its fruits that are consumed fresh or dried. It is indispensable in African cuisine as a spice. The seeds planted were of the F1-Goliath variety that produces sweet fruits with a maturity of 60 to 70 days after emergence. Bremer et al. [27] classified tomato (Solanum lycopersicum L.) as a member of the family Solanaceae, which is synonymous with the species Lycopersicon esculentum Mill. It is widely consumed as a fruit vegetable and used in processing for jam, tomato pastes and purees among others. The seeds studied were of the Cobra F1 variety, with square fruits and high disease resistance. Hassan et al. [28] reported that tomato is one of the most important vegetables worldwide. It is rich in minerals, vitamins, essential amino acids, sugars and dietary fibers and contains much vitamin B and C, iron and phosphorus. The fourth species studied was watermelon (Citrulus lanatus (Thunb.) Matsum. \& Nakai), a member of the Family Cucurbitaceae. It is highly priced worldwide as a fruit, and mainly consumed fresh or processed into juices. The variety studied was the Logone F1, which is oblong in shape, with bright red flesh and highly resistant to Fusarium wilt. It matures 80 to 81 days after emergence. All seeds were produced by Technisem Inc. (France) and bought from a local farmers' shop. We chose these crops due to their economic relevance and prevalence in the study site.

\subsection{Study site}

The screen house used for the experiment is located within the SOWEFCU (South West Farmers' Cooperative Union) premises in Kumba, Meme Division, Cameroon. The site coordinates are as follows: $04.628^{\circ} 58^{\prime N} \mathrm{~N}$ latitude and 009.444 98"E longitude, at an altitude of about $237 \mathrm{~m}$ asl (Figure 1). Kumba falls within the Cameroon Agro-ecological Zone IV characterized by monomodal rainfall, with one dry- and one rainy season. Mean annual temperature stands at $25^{\circ} \mathrm{C}$ and the total average rainfall in the subdivision is about $2200 \mathrm{~mm}$ (IRAD- Barombi, Unpublished data), and the natural vegetation is equatorial forest. Agriculture is the backbone of the economy, and while watermelon, beans and 
pepper are traditionally grown here, tomato is an emergent crop in the area because it typically does better in cooler climates.

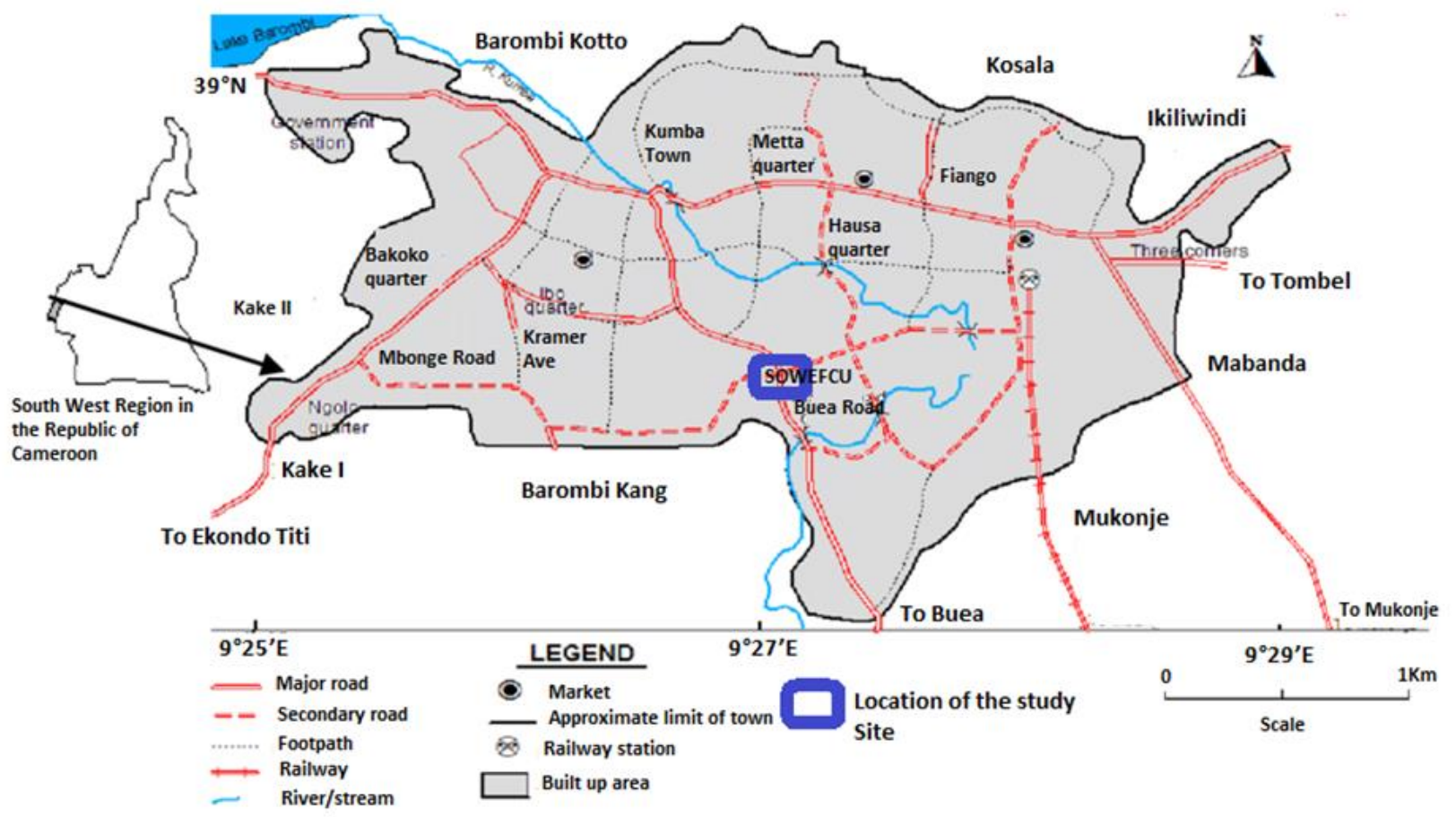

Figure 1 Map of Kumba Municipality showing the study site at SOWEFCU (Adapted from the Department of Town Planning, Kumba Urban Council, 2015)

\subsection{Growth conditions in screenhouse}

The screenhouse measured $16 \mathrm{~m}$ by $4 \mathrm{~m}$. It was built to have adequate light transmission quality and ambient $\mathrm{CO}_{2}$ levels. The walls were screened with mesh to keep out predators. During the experiment, temperature within the screenhouse ranged from 24.5 to $41.5{ }^{\circ} \mathrm{C}$ with a relative humidity range of 49 to $80.5 \%$ at midday.

\subsection{Experimental design and treatments}

A complete randomized design (CRD) was used, and the main factor was irrigation. There were four experimental levels with three replicates making 12 experimental units. The irrigation levels considered were $0,0.1,0.2$ and $0.3 \mathrm{~L}$ per pot per week. The $0.1 \mathrm{~L}$ irrigation per pot was computed from the mean annual precipitation of $2200 \mathrm{~mm}$ for the region, and then standardized per surface area of the experimental pots. The other treatments were then set to reflect different irrigation scenarios, within the context of the predicted changing rainfall patterns. That is, Irrigation levels $0 \mathrm{~L}$ per pot (equivalent to drought), and 0.2 and $0.3 \mathrm{~L}$ per pot (equivalent precipitation of $3300 \mathrm{~mm}$ and $4400 \mathrm{~mm}$ per year) representing higher than normal precipitation scenarios in the region.

\subsection{Agronomic operations and treatments application}

Loamy-clay soil from the top $30 \mathrm{~cm}$ was collected, homogenized and used to fill plastic containers measuring $11.5 \mathrm{~cm} \times$ $8 \mathrm{~cm}$. Four holes at equidistance were punctured at the base of each plastic pot to prevent water stagnation, and infiltrated water was collected and returned to the pots to maintain moisture levels. The soil was well irrigated with freshwater before seeding, and irrigation continued with freshwater until treatment application. All plants were raised from seeds within the pots. All seeds were planted within the top $2 \mathrm{~cm}$ of soil in the pots. Germination occurred between 3 - 5 days for the beans, watermelons while that for pepper and tomato occurred after 7 days. After germination the seedlings were thinned to three (3) per pot. Systemic fungicide (Manconxyl Plus 720) was sprayed on the seedlings to control fungi attack.

The seedlings were allowed to grow up to the three leaves stage before treatments were applied. These were irrigated with $0.1 \mathrm{~L}$ of freshwater twice a week (split irrigation). This irrigation volume was calculated from mean annual precipitation of $2200 \mathrm{~mm}$ for the region. After the seedlings had developed at least 3 leaves per plants (within two 
weeks), the various treatments were implemented. For the no irrigation treatment, water was withheld from the start of treatments; for the other treatments, plants were irrigated with $0.1,0.2$ and $0.3 \mathrm{~L}$ of freshwater per week in 2 split applications.

\subsection{Data collection}

\subsubsection{Growth measurements}

These measurements were made every three days, for two weeks. Leaf lengths and widths of the first fully developed leaves of each seedling per treatment were measured using a meter rule from the petiole to the tip of the leaf, and at three points across the leaf respectively, every three days for two weeks. These measurements were used to calculate the relative leaf area.

For each plant, height was measured using a meter rule from the ground level to the terminal growth point every three days. The shoot collar diameter of each seedling was measured below the first leaves using a digital caliper, and number of leaves was determined by counting.

\subsubsection{Ecophysiological measurements}

Relative humidity and temperature

These were measured at midday using the ACURITE Thermometer and Relative Humidity meter. This data was used to describe growth conditions and explain results.

\section{Photosynthetic efficiency}

This was determined by measuring the Chlorophyll Fluorescence using the Hansatech Pocket Plant Efficiency Analyzer (PEA) (Hansatech Instruments Ltd., Norfolk, UK). The plants were dark adapted as follows: tomatoes (8 minutes), pepper ( 8 minutes), beans ( 8 minutes) and watermelon ( 2 minutes). These dark adaptation times were determined a priori by measuring photosynthetic efficiency over 30 seconds interval on plants of each species, and the time for maximum photosynthetic efficiency recorded as the dark adaptation time for the species. After dark adaptation, the chlorophyll florescence was recorded immediately, after illuminating with a single actinic light source at an intensity of $3500 \mu \mathrm{mol} \mathrm{m}^{-2} \mathrm{~s}^{-1}$. All measurements were taken at midday.

\section{Destructive sampling}

After two weeks of treatment, the experiment was terminated. The pots were saturated with water and allowed for thirty minutes to loosen the soil, after which the seedlings were carefully removed from the pots. They were washed with clean water and dried using tissue paper. After this, the roots were separated from the shoots and the masses of shoots and roots measured using a digital balance (200mg max). These data were used in the determination of root/shoot ratios and calculation of Water Use Efficiency.

\subsection{Data analyses}

The relative growth rate (RGR) was calculated from the initial and final plant mass as follows:

$$
R G R\left(\frac{c m}{w k}\right)=\frac{L N W 2-L N W 1}{t 2-t 1}
$$

Where $\mathrm{LN}=$ natural logarithm, $\mathrm{W} 2$ = final biomass, $\mathrm{H} 1$ = initial biomass, $\mathrm{t}=$ time in days .

The ratio of the roots to the shoot was calculated after separation of roots from shoots.

Root: shoot ratio $=\frac{\text { root mass }(g)}{\text { shoot mass }(g)}$

Water use efficiency (WUE) was calculated as the ratio between the total plants biomass (g) produced and the total amount of water (L) applied during irrigation.

WUE $\left(\frac{\mathrm{g}}{\mathrm{L}}\right)=\frac{\text { total plants biomass }}{\text { Total amount of water applied }}$ 
These and other data was subjected to tests for normality and equality of variances, after which One Way Analysis of variance coupled with Tukey HSD pairwise comparison was done to test for significance of treatment effects and compare means. Pearson correlation was used to determine the data covariance and other relationships between parameters. All analyses were conducted in the MINITAB Version 17 statistical package (MINITAB Inc. PA, USA) at $\alpha=$ 0.05. Charts were produced in Microsoft Excel 2013 (Microsoft Inc. USA).

\section{Results}

\subsection{Effects of irrigation on growth}

Irrigation significantly affected heights, number of leaves and relative leaf area of all species $(p<0.05)$. Except for watermelon, plant height increased significantly as irrigation volume increased, with the tallest plants found in pots treated with $0.3 \mathrm{~L}$ of irrigation water per week (Figure 2). The greatest increase in height was found in beans plants, with a difference of $21.1 \mathrm{~cm}$ between plants treated with $0.3 \mathrm{~L}$ per week and those under the drought treatment. This height difference with treatment was $0.93,1.27$ and $1.01 \mathrm{~cm}$ for pepper, tomato and watermelon seedlings respectively. Leaf numbers also increased as irrigation water increased, with more leaves counted in plants treated with $0.3 \mathrm{~L}$ irrigation water for all species except tomato. Over time, plant height and number of leaves increased (Figure 2) Relative leaf area and seedling shoot collar diameter (data not shown) increased with treatment, but this increase was not statistically significant.

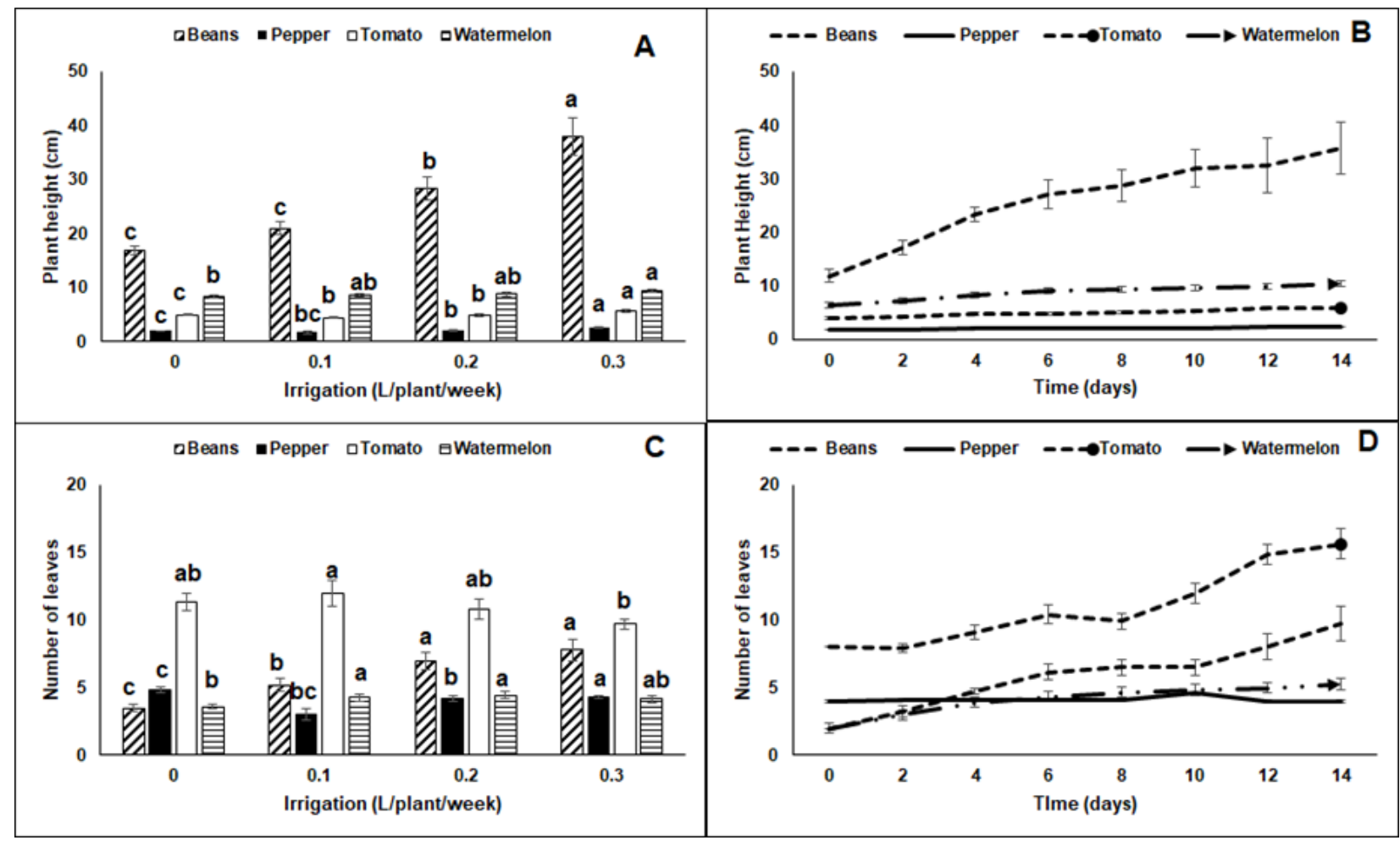

Figure 2 Effects of irrigation on growth parameters of beans, pepper, tomato and water melon seedlings over 12 days. Bars and data points on lines represent means \pm Standard Error. Means separated through One-way ANOVA with Tukey HSD at $\alpha=0.05$. Bars with the same letter for each species are not statistically different.

\subsection{Effects of treatments on RGR}

Relative growth rates of the different species are presented in Figure 3, which shows that RGR of beans and watermelon increased with increase in volume of irrigation water. For beans, the highest RGR $\left(0.12 \mathrm{~g} \mathrm{~g}^{-1}\right.$ day $\left.^{-1}\right)$ was recorded in plants treated with the highest irrigation volume $(0.3 \mathrm{~L} /$ pot/week). Similarly, for watermelon, highest RGR $(0.03 \mathrm{~g}$ gday $^{-1}$ ) was recorded in plants treated with the highest irrigation volume. On the other hand, the other species exhibited negative relative growth rates (Figure 3). 


\subsection{Effects of irrigation on biomass}

Biomass of seedlings increased as irrigation water increased (Figure 4). The difference in biomass between the highest irrigation volume and the control (no irrigation) was $4.37 \mathrm{~g}$ for beans, $0.037 \mathrm{~g}$ for pepper, $0.383 \mathrm{~g}$ for tomato and 1.003 $\mathrm{g}$ for watermelon seedlings.

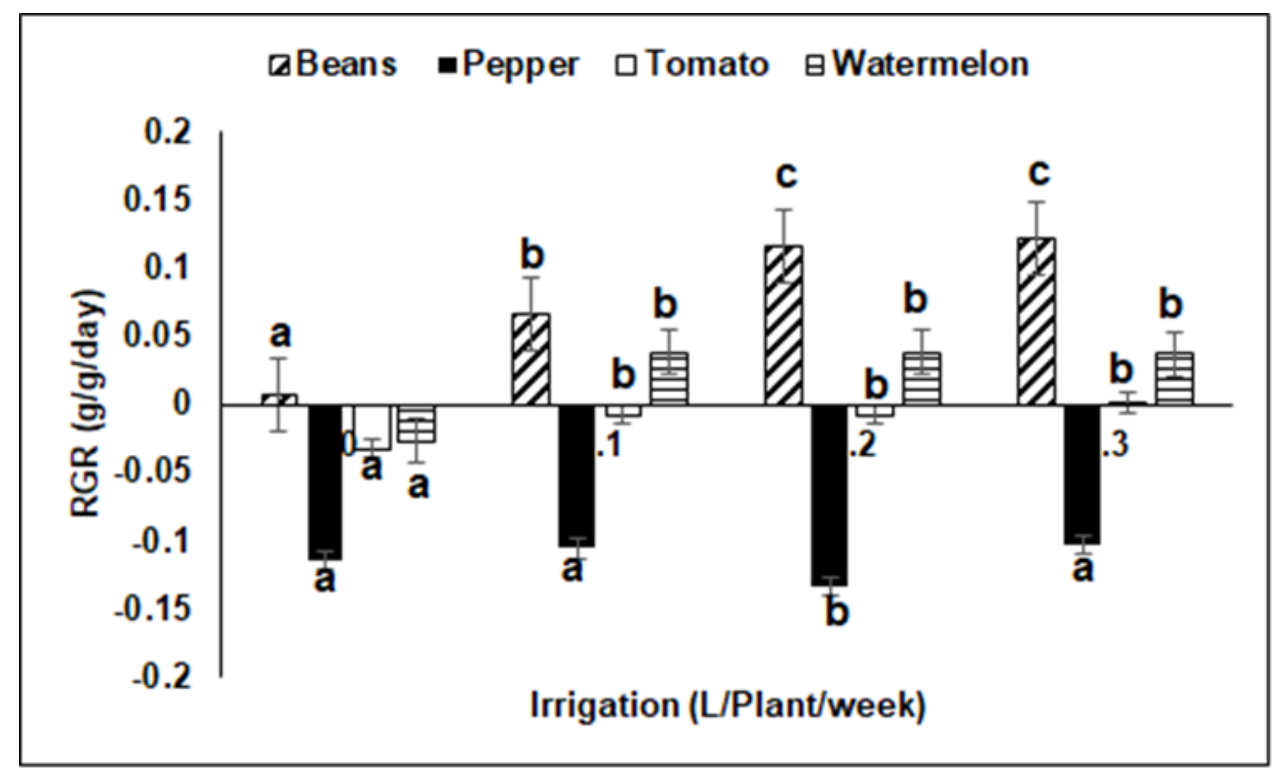

Figure 3 Effects of irrigation on RGR of beans, pepper, tomato and water melon seedlings over 12 days. Bars represent means \pm Standard error. Means separated through One-way ANOVA with Tukey HSD at $\alpha=0.05$. Bars with the same letter for each species are not statistically different

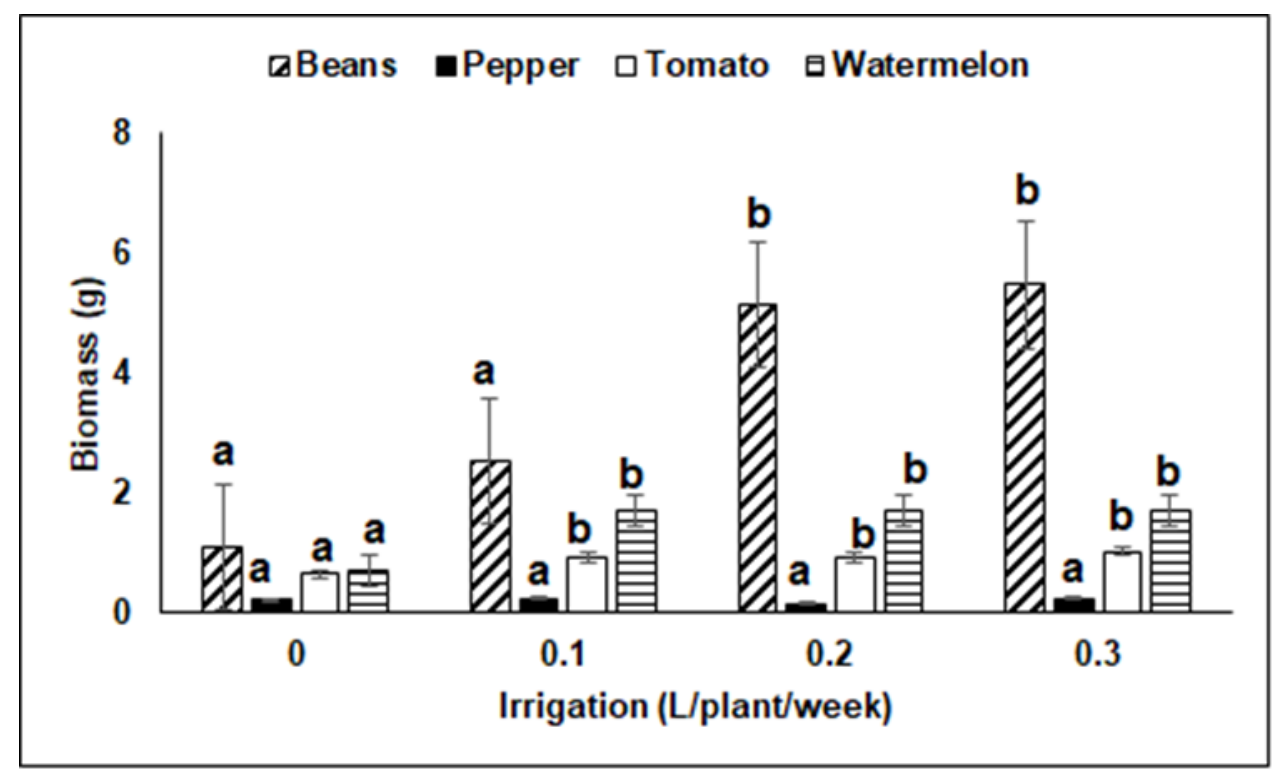

Figure 4 Effects of irrigation on biomass of beans, pepper, tomato and water melon seedlings over 12 days. Bars represent means \pm standard error. Means separated through One-way ANOVA with Tukey HSD at $\alpha=0.05$. Bars with the same letter for each species are not statistically different

\subsection{Effect of irrigation on chlorophyll fluorescence}

The analysis of variance showed that only photosynthetic efficiency of pepper was significantly $(p<0.05)$ affected by irrigation. For beans seedlings, chlorophyll fluorescence values were statistically around the 0.8 value for healthy plants. Similarly, fluorescence values for watermelon of about 0.75 are not much lower than expected. Pepper and tomato seedlings subjected to drought show diminished photosynthetic efficiency (Table 1). 
Table 1 Chlorophyll fluorescence as affected by irrigation level

\begin{tabular}{|l|l|l|l|l|}
\hline Irrigation (L/week) & Beans & Pepper & Tomato & Watermelon \\
\hline 0 & $0.701 \mathrm{a}$ & $0.45 \mathrm{~b}$ & $0.679 \mathrm{a}$ & $0.75 \mathrm{a}$ \\
\hline 0.1 & $0.867 \mathrm{a}$ & $0.68 \mathrm{a}$ & $0.74 \mathrm{a}$ & $0.76 \mathrm{a}$ \\
\hline 0.2 & $0.807 \mathrm{a}$ & $0.63 \mathrm{a}$ & $0.712 \mathrm{a}$ & $0.76 \mathrm{a}$ \\
\hline 0.3 & $0.784 \mathrm{a}$ & $0.695 \mathrm{a}$ & $0.70 \mathrm{a}$ & $0.75 \mathrm{a}$ \\
\hline
\end{tabular}

Values represent means. Means separated through One-way ANOVA with Tukey HSD test at $\alpha=0.05$. Means with the same letter within the same column are not significantly different.

\subsection{Effect of treatments on root: shoot ratio}

Table 2 presents the root:shoot ratio of the species under study. Irrigation level significantly $(\mathrm{p}<0.05)$ affected root: shoot ratio of watermelon seedlings. The same was not observed for the other species. As irrigation level increased, the ratio of roots to shoots decreased.

Table 2 Root shoot ratio of beans, pepper, tomato and watermelon as affected by irrigation levels

\begin{tabular}{|l|l|l|l|l|}
\hline Irrigation (L/week) & Beans & Pepper & Tomato & Watermelon \\
\hline 0 & $1.06 \mathrm{a}$ & $0.76 \mathrm{a}$ & $0.31 \mathrm{ab}$ & $0.27 \mathrm{a}$ \\
\hline 0.1 & $0.90 \mathrm{a}$ & $0.45 \mathrm{a}$ & $0.323 \mathrm{ab}$ & $0.115 \mathrm{~b}$ \\
\hline 0.2 & $0.81 \mathrm{a}$ & $0.66 \mathrm{a}$ & $0.58 \mathrm{a}$ & $0.198 \mathrm{ab}$ \\
\hline 0.3 & $0.73 \mathrm{a}$ & $0.68 \mathrm{a}$ & $0.180 \mathrm{~b}$ & $0.208 \mathrm{ab}$ \\
\hline
\end{tabular}

Values represent means. Means separated through One-way ANOVA with Tukey HSD test at $\alpha=0.05$. Means with the same letter within the same column are not significantly different.

\subsection{Effects of irrigation levels on water use efficiency of beans, pepper, tomato and watermelon}

Table 3 shows the water use efficiency of the seedlings under study. For all species WUE decreased significantly as irrigation volume increased. Seedlings irrigated with $0.3 \mathrm{~L}$ of water had the least WUE compared with those not irrigated. The decrease in WUE was 59.73, 14.18, 44.9 and $44.6 \mathrm{~g} / \mathrm{l}$ for beans, pepper, tomato and watermelon respectively as irrigation volume increased from 0 to $0.3 \mathrm{l} /$ pot/week.

Table 3 Water use efficiency as affected by irrigation $(\mathrm{g} / \mathrm{l})$

\begin{tabular}{|l|l|l|l|l|}
\hline Irrigation (L/week) & Beans & Pepper & Tomato & Watermelon \\
\hline 0 & $85.4 \mathrm{a}$ & $15.38 \mathrm{a}$ & $49.0 \mathrm{a}$ & $53.08 \mathrm{a}$ \\
\hline 0.1 & $36.04 \mathrm{~b}$ & $4.03 \mathrm{~b}$ & $11.72 \mathrm{~b}$ & $22.84 \mathrm{~b}$ \\
\hline 0.2 & $42.05 \mathrm{~b}$ & $1.3 \mathrm{~b}$ & $11.18 \mathrm{~b}$ & $13.80 \mathrm{bc}$ \\
\hline 0.3 & $25.67 \mathrm{~b}$ & $1.2 \mathrm{~b}$ & $4.083 \mathrm{~b}$ & $8.47 \mathrm{c}$ \\
\hline
\end{tabular}

Values represent means. Means separated through One-way ANOVA with Tukey HSD test at $\alpha=0.05$. Means with the same letter within the same column are not significantly different.

\subsection{Correlation}

Figure 5 shows some key correlation results of irrigation, growth and physiology parameters. For all species, plant height correlated positively with irrigation levels. Relative growth rates of beans correlated positively with irrigation volume $(r=0.997)$ but this correlation was not found for the other species. Root:shoot ratio of beans correlated negatively $(r=-0.985)$ with irrigation levels. Negative patterns were observed between WUE and irrigation levels but this correlation was not significant. Similarly, there were no correlations between $\mathrm{fv} / \mathrm{fm}$ and irrigation levels for all species. 

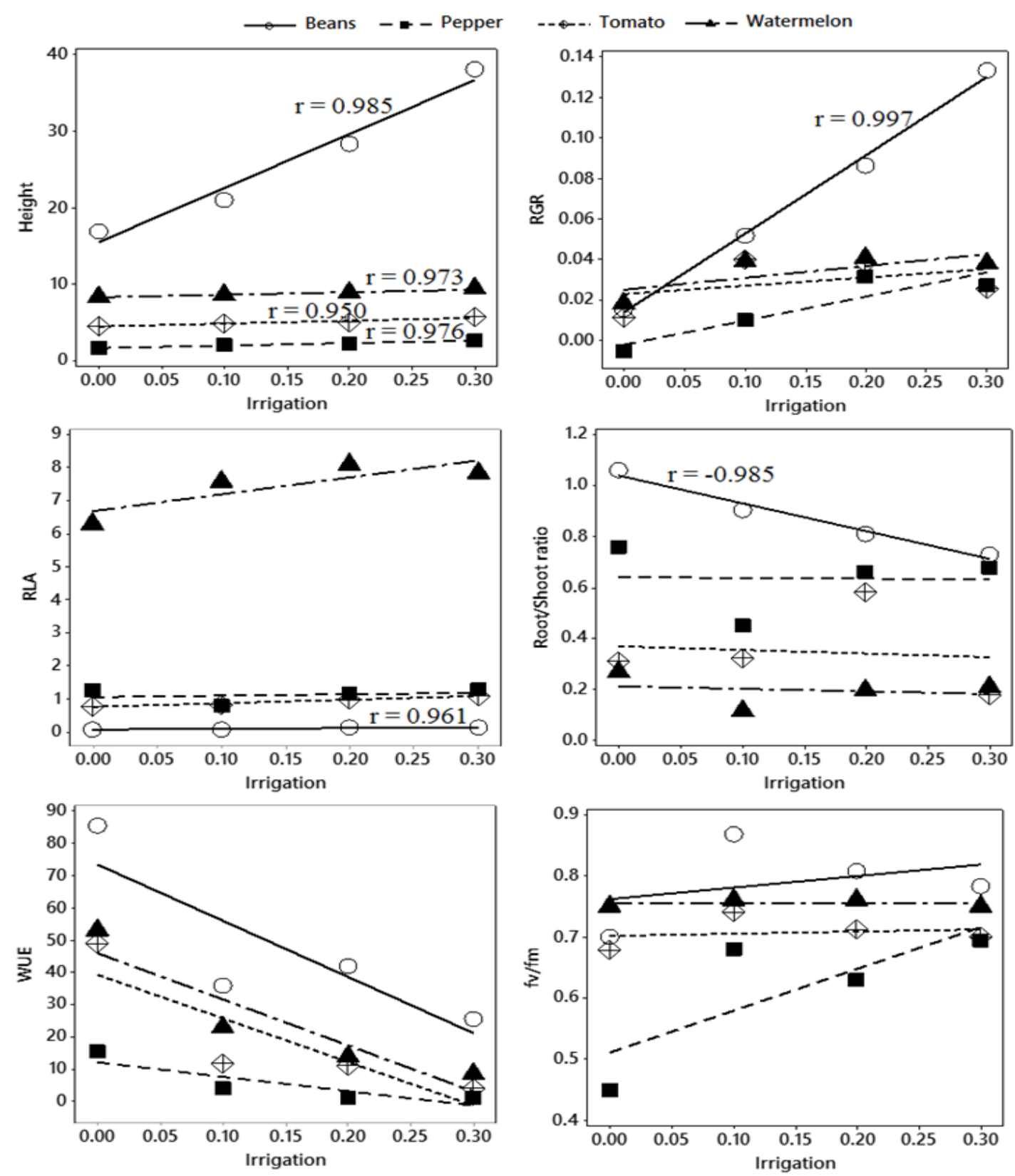

Figure 5 Correlation of irrigation levels, growth, and physiological parameters of beans, pepper, tomato and watermelon. The " $r$ " values are shown only for significant correlations.

\section{Discussion}

The aim of this study was to assess the impact of water stress or varying irrigation levels on early seedling growth, yield and quantum efficiency responses of beans, pepper, and tomato and watermelon seedlings. It seeks to understand seedlings' ecophysiological tolerances to varying irrigation and is not a comparative study between the species because stress responses of plants are dependent among other things on the age of the plant involved [24] and most importantly their genetic makeup. Our work focused on early seedling stages (One week for establishment post emergence and two weeks of treatments) for which comparable studies are rare in the literature. Notwithstanding, results showed that plants grew better as irrigation increased from 0 irrigation, indicating that the no irrigation treatment had negative implications on seedling growth, as expected. Increased growth coincided with leaf number and other growth attributes which are covariates. There was a growth threshold for irrigation. Values of RGR show that for beans and watermelon seedlings, irrigation volume higher than $0.2 \mathrm{l}$ /week would not significantly increase the relative growth rate of seedlings, while pepper and tomato seedlings exhibited negative values which indicate they were extremely stressed to a point where vegetative growth practically stopped. Sharifi [31] showed increasing growth and RLA in maize seedlings 
as irrigation volume increased, hence consistent with our findings of low RLA in the no irrigation treatment. Growth was accompanied by biomass accumulation, which increased with irrigation volume for all species. This increase was however simultaneous with increased water use inefficiency since WUE dropped significantly as irrigation volume increased. Lowry and Smith [25] have reported that increasing RGR is an essential indicator of how well species are adapted to compete for resources, and hence our results suggest that under the irrigation regimes studied, beans and watermelon are well-adapted to grow with high vigor, while pepper and tomato suffer retarded growth and would not compete well for nutrients and other resources under these conditions. With respect to WUE, our findings are consistent with those of other authors who have shown that in tolerant plants or conditions of below-lethal drought stress, there are improvements in WUE either as a result of better stomatal control or of reduced plant vigor [32, 33, 34]. Where irrigation improves WUE, further gains can only be maintained by irrigation suppression, as has been shown for cotton [35]. Hence suppression of vigor can be expected in water stressed plants, while over-irrigation also suppresses plant growth, probably a result of reduced roots respiration. It was expected that root growth of seedlings would be boosted in the dryer conditions as they forage the soil for scarce moisture. In seedlings of rice for example, root mass was augmented as a result of translocation of higher proportion of dry matter and soluble sugar from shoots to roots, and this was mediated by increase in leaf sucrose-phosphate synthase and root invertase activity [23]. These patterns were observed in beans and pepper seedlings in the current study, but those of tomato and watermelon did not present clear trends. The reverse is also true, that is, reduction of root mass under adequate irrigation. Under well-watered conditions, root length densities have been shown to decline exponentially with depth because of limited oxygen diffusion rate [36]. Hence where irrigation is enough, most roots forage on the near surface, effectively reducing root mass and root:shoot ratios. In such well-irrigated situations also, we expect the plant to present the most efficient physiology. In this experiment, we measured the quantum efficiency of PSII photochemistry, where as a rule, the value of 0.8 is representative of a normal healthy plant, and values below this indicate inefficient photosynthesis due to the imposed stress [37]. Beans seedlings improved under irrigation to $\mathrm{fv} / \mathrm{fm}$ values of 0.8 compared to 0.7 under the no irrigation control, showing that control plants were stressed and irrigation was necessary to alleviate this stress. This is consistent with findings by Liberato et al. [32] who reported a 10\% drop in quantum efficiency of PSII photochemistry following 25 days of water stress on Minquartia guianensis Aubl. seedlings, but this efficiency of photochemistry was regained as the imposed stress was removed. Similar results were found for watermelon seedlings, while pepper and tomato seedlings displayed inefficient photochemistry due to the imposed treatments. The lack of correlation between irrigation volume and the quantum efficiency of photosynthesis suggests that factors other than the imposed treatment also influenced the physiology of the plants studied. Such factors could include the initial nutrient reserves of the different seeds. These results suggest that significant changes occur in the seed nutrient metabolisms during germination and early seedling growth period of plants. In consequence, all seedlings survived in water deficit conditions, but do progressively well as irrigation water is increased. Mechanisms for drought tolerance have been reported e.g. reduced leaf area, leaf abscission, increased rate of photosynthesis [24] and root traits such as shoot-toroot retranslocation [38] most of which become evident in seedlings at a later stage. Seedlings of pepper and tomato were more sensitive to both drought and excess irrigation and would require more careful management of irrigation regimes in field cultivation.

\section{Conclusion}

Our Results show that seedlings respond to varying irrigation in the early days of growth, and both limited irrigation and excess irrigation water would adversely affect seedling performance. Therefore, appropriate management of irrigation in rain fed crop lands would be required to retain seedling growth vigor for better productivity in the context of increasing water limitation and climate change.

\section{Compliance with ethical standards}

\section{Acknowledgments}

We thank the South West Farmers' Cooperative Union for providing premises for the screenhouse to be constructed, and the Department of Botany and Plant Physiology for providing relevant equipment. We thank the independent reviewers for excellent contributions to this manuscript.

\section{Disclosure of conflict of interest}

The authors declare that there is no conflict of interest. 


\section{References}

[1] Lal R and Stewart BA. (1990). Soil degradation. Springer-Verlag, New York, USA.

[2] Milano M, Ruelland D, Fernandez S, Dezetter A, Fabre J, Servat E, Fritsch JM, Ardoin-Bardin S and Thivet G. (2013). Current state of Mediterranean water resources and future trends under climatic and anthropogenic changes. Hydrological Sciences Journal, 58(3), 498-518.

[3] Bartels D and Sunkar R. (2005). Drought and salt tolerance in plants. Critical Reviews in Plant Science, 24, 23-58.

[4] Reynolds TW, Waddington SR, Anderson CL and Chew A. (2015). Environmental impacts and constraints associated with the production of major food crops in Sub-Saharan Africa and South Asia. Food Security 7, 795822 .

[5] Hussain HA, Hussain S, Khaliq A, Ashraf U, Anjum SA, Men S and Wang L. (2018). Chilling and Drought Stresses in Crop Plants: Implications, Cross Talk, and Potential Management Opportunities. Frontiers in Plant Sciences, 9, 393.

[6] Buchanan B, Gruissem W and Jones R. (2000). Biochemistry and Molecular Biology of Plants. American Society of Plant Physiology, Rockville, 1158-120.

[7] Rosenzweig C, Iglesius A, Yang XB, Epstein PR and Chivian E. (2001). Climate change and extreme weather events - Implications for food production, plant diseases, and pests. NASA Publications, 24.

[8] Zhang Y, Kendy E, Qiang Y, Changming L, Yanjun S and Hongyong, S. (2004). Effect of soil water deficit on evapotranspiration, crop yield, and water use efficiency in the North China Plain. Agricultural Water Management, 64(2), 107-122.

[9] Perera ACS, Gunawardena ERN and Punyawardena BVR. (2016). Relationship between soil moisture deficit and productivity of paddy lands in a major irrigation system in Intermediate zone of Sri Lanka. Tropical Agricultural Research, 27(3), $295-304$.

[10] Butler R. (2012). Soil erosion and its effects. Rainforests.

[11] Hua W, Zhou L, Chen H, Nicholson SE, Raghavendra A and Jiang Y. (2016). Possible causes of the Central Equatorial African long-term drought. Environmental Research Letters, 11(12).

[12] Trenberth KE, Dai A, van der Schrier G, Jones PD, Barichivich J, Briffa KR and Sheffield J. (2014). Global warming and changes in drought. Nature Climate Change, 4, 17-22.

[13] Toselli M, Flore JA, Marogoni B and Masia A. (1999). Effects of root-zone temperature on nitrogen accumulation by non-breeding apple trees. Journal of horticultural Science and Biotechnology, 74, 118-124.

[14] Shinozaki K and Yamaguchi-Shinozaki K. (2000). Molecular responses to dehydration and low temperature: differences and cross-talk between two stress signaling pathways. Current Opinion in Plant Biology, 3(3), 217223.

[15] Chaves, MM, Maroco JP and Pereira JS. (2003). Understanding plant responses to drought - from genes to the whole plant. Functional Plant Biology, 30, 239-264.

[16] Sinclair TR. (2011). Challenges in breeding for yield increase for drought. Trends in Plant Science, 16(6), 289293.

[17] Mickelbart M, Hasegawa P and Bailey-Serres J. (2015). Genetic mechanisms of abiotic stress tolerance that translate to crop yield stability. Nature Reviews Genetics, 16, 237-251.

[18] Chen Z, Xu J, Wang F, Wang L and Xu Z. (2019). Morpho-physiological and proteomic responses to water stress in two contrasting tobacco varieties. Scientific Reports, 9, 18523.

[19] Herms DA and Mattson WJ. (1992).The dilemma of plants: To grow or defend. The Quarterly Review of Biology, 67(3), 283-335.

[20] Assefa Y, Staggenborg SA and Prasad VPV. (2010). Grain sorghum water requirement and responses to drought stress: A review. [Online]. Crop Management.

[21] Farooq M, Wahid A, Kobayashi N, Fujita D and Basra SMA. (2009). Plant Drought Stress: Effects, Mechanisms and Management. In: Lichtfouse E, Navarrete M, Debaeke P, Véronique S and Alberola C. (eds) Sustainable Agriculture. Springer, Dordrecht. 
[22] Anjum SA, Xie X., Wang L, Saleem MF, Man C and Lei W. (2011). Morphological, physiological and biochemical responses of plants to drought stress. African Journal of Agricultural Research, 6(9), 2026-2032.

[23] Xu W, Cui K, Xu A, Nie L, Huang J and Peng S. (2015). Drought stress condition increases root to shoot ratio via alteration of carbohydrate partitioning and enzymatic activity in rice seedlings. Acta Physiologiae Plantarum, $37(9)$.

[24] Waseem M, Ali A, Tahir M, Nadeem MA, Ayub M, Tanveer A, Ahmad R and Hussain M. (2011). Mechanism of drought tolerance in plant and its management through different methods. Continental Journal of Agricultural Science, 5(1), 10-25.

[25] Lowry CJ and Smith RG. (2018). Weed control through crop plant manipulations. In. Non-Chemical Weed Control. Durham, New Hampshire.

[26] Berinyuy JE and Fontem DA. (2011). Evaluating post-harvest opportunities and constraints to utilization and marketing of African leafy vegetables in Cameroon. African Journal of Food, Agriculture, Nutrition and Development, 11(2), 4647-4663.

[27] Bremer B, Bremer K, Chase MW, Fay MF, Reveal JL, Soltis DE, Soltis PS, Stevens PF, Anderberg AA, Moore MJ and Olmstead RG. 2009. An update of the Angiosperm Phylogeny Group classification for the orders and families of flowering plants: APG III. Botanical Journal of the Linnaean Society, 161, 105-121.

[28] Hassan MA, Fuertes MM, Sánchez FJS, Vicente 0 and Boscaiu M. (2015). Effects of Salt and Water Stress on Plant Growth and on Accumulation of Osmolytes and Antioxidant Compounds in Cherry Tomato. Notulae Botanicae Horti Agrobotanici, 43(1), 1-11.

[29] Tabot PT and Adams JB. (2012). Morphological and Physiological responses of Triglochin buchenaui Kocke, Mering \& Kadereit to various combinations of water and salinity: implications for resilience to climate change. Wetlands Ecology and Management, 20, 373-388.

[30] Egbe EA, Forkwa EY, Ayamoh EE. (2014). Evaluation of Seedlings of Three Woody Species under Four Soil Moisture Capacities. British Journal of Applied Science and Technology, 4(24), 3455-3472.

[31] Sharifi P. (2017). Studying Maize Growth Indices in Different Water Stress Conditions and the Use of Humic Acid. Biomedical and Pharmacological Journal, 10(10), 303-310.

[32] Liberato MAR, Gonçalves JF, Chevreuil LR, da Rocha Nina Junior A, Fernandes AV and dos Santos Junior UM. (2006). Leaf water potential, gas exchange and chlorophyll a fluorescence in acariquara seedlings (Minquartia guianensis Aubl.) under water stress and recovery. Brazilian Journal of Plant Physiology, 18(2), 315-323.

[33] Souza CR, Maroco PJ, dos Santos TP, Rodrigues ML, Lopes CM, Pereira JS and Chaves MM. (2005). Impact of deficit irrigation on water use efficiency and carbon isotope composition (d13C) of field-grown grapevines under Mediterranean climate. Journal of Experimental Botany, 56(418), 2163-2172.

[34] Ali S, Xu Y, Ma X, Ahmad I, Kamran M, Dong Z, Cai, T, Jia Q, Ren X, Zhang P and Jia Z. 2017. Planting Patterns and Deficit Irrigation Strategies to Improve Wheat Production and Water Use Efficiency under Simulated Rainfall Conditions. Frontiers in Plant Sciences, 8.

[35] Silva VGF, de Andrade AP, Fernandes PD, de F da Silva IF, de Azevedo CAV and Araújo, JS. (2010). Productive characteristics and water use efficiency in cotton plants under different irrigation strategies. Revista Brasileira de Engenharia Agrícola e Ambiental, 14(5), 451-457.

[36] Klepper B. (1991). Crop root system response to irrigation. Irrigation Science, 12(3), 105-108.

[37] Woo NS, Badger MR and Pogson BJ. (2008). A rapid, non-invasive procedure for quantitative assessment of drought survival using chlorophyll fluorescence. Plant Methods, 4 (27), 1746-4811.

[38] Fang Y and Xiong L. (2015). General mechanisms of drought response and their application in drought resistance improvement in plants. Cellular and Molecular Life Sciences, 72, 673. 